OPEN ACCESS

Edited by:

Amy Claire Reichelt,

RMIT University, Australia

Reviewed by:

Sandeep Sharma,

University of Calgary, Canada

Annadora Bruce-Keller, Pennington Biomedical Research Center, Louisiana State University,

USA

*Correspondence:

Scott E. Kanosk

kanoski@usc.edu

Received: 14 November 2016

Accepted: 11 January 2017

Published: 30 January 2017

Citation:

Noble EE, Hsu TM and Kanoski SE

(2017) Gut to Brain Dysbiosis:

Mechanisms Linking Western Diet

Consumption, the Microbiome, and

Cognitive Impairment.

Front. Behav. Neurosci. 11:9.

doi: 10.3389/fnbeh.2017.00009

\section{Gut to Brain Dysbiosis: Mechanisms Linking Western Diet Consumption, the Microbiome, and Cognitive Impairment}

\author{
Emily E. Noble ${ }^{1}$, Ted M. Hsu ${ }^{1,2}$ and Scott E. Kanoski ${ }^{1,2 *}$ \\ ${ }^{1}$ Human and Evolutionary Biology Section, Department of Biological Sciences, University of Southern California, Los \\ Angeles, CA, USA, ${ }^{2}$ Neuroscience Program, University of Southern California, Los Angeles, CA, USA
}

Consumption of a Western Diet (WD) that is high in saturated fat and added sugars negatively impacts cognitive function, particularly mnemonic processes that rely on the integrity of the hippocampus. Emerging evidence suggests that the gut microbiome influences cognitive function via the gut-brain axis, and that WD factors significantly alter the proportions of commensal bacteria in the gastrointestinal tract. Here we review mechanisms through which consuming a WD negatively impacts neurocognitive function, with a particular focus on recent evidence linking the gut microbiome with dietary- and metabolic-associated hippocampal impairment. We highlight evidence linking gut bacteria to altered intestinal permeability and blood brain barrier integrity, thus making the brain more vulnerable to the influx of deleterious substances from the circulation. WD consumption also increases production of endotoxin by commensal bacteria, which may promote neuroinflammation and cognitive dysfunction. Recent findings also show that diet-induced alterations in gut microbiota impair peripheral insulin sensitivity, which is associated with hippocampal neuronal derrangements and associated mnemonic deficits. In some cases treatment with specific probiotics or prebiotics can prevent or reverse some of the deleterious impact of WD consumption on neuropsychological outcomes, indicating that targeting the microbiome may be a successful strategy for combating dietary- and metabolic-associated cognitive impairment.

Keywords: neuroinflammation, insulin, gut bacteria, sugar, fat, endotoxin, hippocampus

\section{INTRODUCTION}

Substantial evidence has linked consumption of a Western Diet (WD), defined here as diets consisting of both high levels of fat $(35-60 \%$ total kcal) and added sugars, with cognitive dysfunction (Molteni et al., 2002, 2004; Kanoski et al., 2007, 2010; Kanoski and Davidson, 2011; Davidson et al., 2012; Francis and Stevenson, 2013; Baym et al., 2014; Beilharz et al., 2014, 2016a,b; Noble et al., 2014; Hsu et al., 2015; Khan et al., 2015b; Noble and Kanoski, 2016). The hippocampus, a brain region associated with the control of certain learning and memory processes, is particularly vulnerable to the deleterious effects of WD intake (Kanoski and Davidson, 2011; Baym et al., 2014; Davidson et al., 2014). The mechanisms through which WD consumption 
impacts the brain are not completely understood, however emerging research has implicated the gut-brain axis as playing a critical role. The gut microbiome (the collective genome of microbes residing in the gastrointestinal tract) has a substantial impact on brain function (Bercik et al., 2011; Davari et al., 2013; Hsiao et al., 2013; Bruce-Keller et al., 2015). Moreover, the gut microbiome is profoundly affected by dietary factors (de La Serre et al., 2010; David et al., 2014; Noble et al., 2017). In this review we raise the hypothesis that the microbiome is a critical link between WD consumption and neurocognitive dysfunction. Putative mechanisms connecting WD consumption, microbiota alterations, and cognitive impairment include barrier integrity (gastrointestinal tract, neurovascular), neuroinflammation, and impaired insulin signaling. Though each topic is considered individually, it is likely that these and other biological outcomes associated with WD consumption work in concert to impact brain function.

\section{WESTERN DIET, HIPPOCAMPAL FUNCTION, AND GUT MICROBIOTA}

Extensive evidence from rodent (reviewed in Kanoski and Davidson, 2011) and human studies (Kalmijn et al., 2004; Francis and Stevenson, 2011; Baym et al., 2014) reveals that consumption of a WD is linked with impaired hippocampal-dependent learning and memory function. Due to the obesity-promoting nature of WD, it is difficult to discern the relative contribution of dietary factors and obesity on cognitive outcomes. However, while obesity per-se is associated with reduced hippocampal volume (Jagust et al., 2005) and impaired hippocampal function (Li et al., 2002; Winocur et al., 2005; Khan et al., 2015a), evidence shows that a WD negatively impacts hippocampal function independent of obesity. For example, hippocampal-dependent spatial memory impairments have been reported after only 3 (Kanoski and Davidson, 2010) or 9 (Murray et al., 2009) days of consuming a WD, despite similar body weights between animals compared to standard chow-fed controls. Similar to WDs, high fructose diets can also impair hippocampal-dependent learning and memory in rodents independent of obesity (Hsu et al., 2015; Agrawal et al., 2016; Meng et al., 2016; Noble and Kanoski, 2016). Together these data suggest that dietary factors common in a WD have the capacity to impart cognitive dysfunction after only a brief exposure, and independent of severe metabolic impairments.

While much progress has been made in elucidating the neurobiological mechanisms underlying WD-associated cognitive impairment (reviewed in Kanoski and Davidson, 2011; Beilharz et al., 2015), few reports consider the gut microbiome, which consists of an estimated 100 trillion microorganisms that reside in the host GI tract (Bäckhed et al., 2005). The gut microbiome has emerged as a major contributor to cognitive health (Gareau et al., 2011; Bajaj et al., 2012; Bruce-Keller et al., 2015; Desbonnet et al., 2015; Fröhlich et al., 2016) and is affected by dietary factors (Daniel et al., 2014; David et al., 2014; Bruce-Keller et al., 2015; Magnusson et al., 2015; Noble et al., 2017). For example, consumption of a WD reduces populations in the phylum Bacteroidetes and increases Firmicutes and Proteobacteria (Hildebrandt et al., 2009; Zhang et al., 2012) in adult rodents. Importantly, these shifts have been associated with cognitive impairments. Magnusson et al., observed that both high fat ( $45 \% \mathrm{kcal}$ from fat) and high sugar ( $70 \% \mathrm{kcal}$ from carbohydrate) diets elevated levels of Clostridiales (Phylum: Firmicutes) and reduced levels of Bacteroidales (Phylum: Bacteroidetes) in rodents, changes that correlated to poor cognitive flexibility (Magnusson et al., 2015). Recent evidence supports a functional link between the gut microbiome and WD-induced cognitive dysfunction. Bruce-Keller and colleagues revealed that fecal/cecal transplantation from adult mice fed a WD to antibiotic pre-treated mice fed a control diet increased anxiety and stereotypic activity and impaired contextual fear conditioning (Bruce-Keller et al., 2015). While the bacterial species or combination of species responsible for the behavioral effects was not identifiable due to the whole microbiome transfer approach, the bacteria Akkermansia muciniphila were substantially ( 5.4 -fold) reduced by the WD, whereas Bilophila sp. were elevated in the WD group and barely detectable in the control group (Bruce-Keller et al., 2015). Notably, A. muciniphila promotes insulin sensitivity and reduces metabolic endotoxemia in mice (Shin et al., 2014) and is negatively associated with metabolic disease, intestinal inflammatory diseases, and autism in humans (reviewed in Derrien et al., 2016). Conversely, Bilophila are positively associated with inflammatory intestinal diseases (Devkota et al., 2012; Jia et al., 2012) and may contribute to neurocognitive abnormalities by promoting inflammation, though this has not been directly tested.

Recent studies examined the individual contributions of particular macronutrients from a WD on the gut microbiome. For example, a high-fat, carbohydrate-free diet $(72 \% \mathrm{kcal}$ from fat) reduces Bifidobacteria (Cani et al., 2007, 2008), which have been shown modulate intestinal barrier function and reduce endotoxin levels in the gut (Griffiths et al., 2004; Wang et al., 2006). Conversely, Jena and colleagues found that a low-fat chow diet supplemented with a $65 \% \mathrm{w} / \mathrm{v}$ fructose solution had no effect on levels of Bifidobacteria (Jena et al., 2014). However, using more moderate concentrations that model commonly consumed sugar sweetened beverages, recent data from our group reveal that Bifidobacteria were elevated following free access to the sugar solutions (and chow and water) relative to controls that were not given sugar (Noble et al., 2017), suggesting that sugar-induced gut microbiome alterations are dependent on the carbohydrate concentration. Data from our recent study further show that consuming the sugar solutions altered gut bacteria at every phylogenetic level, including significant group effects in $\sim 25 \%$ of gut bacteria at the family level. Similar to animals on very high doses of fructose solution (Jena et al., 2014), our data revealed that sugar consumption elevated Enterobacteriaceae, which are associated with gut (Lupp et al., 2007) and brain inflammation, and poor cognition in hepatic encephalopathy (Bajaj et al., 2012; Ahluwalia et al., 2016). Surprisingly, rodents consuming $11 \%$ concentrations of sugar solutions have elevated levels of Lactobacilli (Noble et al., 2017), which are anti-inflammatory, whereas rodents 
consuming much higher concentrations of sugar solutions (Jena et al., 2014) or dietary fat (Lecomte et al., 2015) have reduced levels of Lactobacilli. Notably, Lactobacilli facilitate short chain fatty acid transport (Kumar et al., 2015). Short chain fatty acids (SCFAs) alter human health and their reduced absorption may be one of the mechanisms by which diet impacts cognitive health via the gut microbiome, a concept reviewed below.

\section{SHORT CHAIN FATTY ACIDS}

SCFAs such as acetate, propionate, and butyrate are produced in the gut by microbial-mediated fermentation of indigestible carbohydrates, such as resistant starch and non-starch polysaccharides from cereals, vegetables, and fruits (MacFarlane and MacFarlane, 2011). The production of SCFAs is significantly reduced in humans within days following a dietary change from a complex carbohydrate rich plant-based diet to an animal based diet high in saturated fat and low in complex carbohydrates (David et al., 2014). Similarly, rodents fed a WD had reduced levels of SCFAs, including acetic, propionic, isobutyric, and isovaleric acids (Ojo et al., 2016) as well as butyric and valeric acids (Berger et al., 2014), compared with controls fed a low-fat chow diet. When taken in context with previously discussed studies demonstrating that shortterm consumption of a WD significantly impacts cognitive function (Kanoski and Davidson, 2010; Beilharz et al., 2014, 2016a,b), the rapid alteration of SCFAs as a putative contributor to WD-induced cognitive dysfunction is temporally feasible.

While the majority of the SCFAs in portal circulation are metabolized by the liver, SCFAs produced in the distal colon bypass portal circulation and reach the brain through circulation (reviewed in MacFabe, 2012). In the brain, SCFAs have a neuroprotective effects (Sun et al., 2015), for example, the salt of the SCFA butyric acid, sodium butyrate, promotes cell proliferation and differentiation in the dentate gyrus, increases the expression of brain-derived neurotrophic factor (BDNF) and glia-derived neurotrophic factor (GDNF), and improves memory performance in the novel object recognition task ( $\mathrm{Wu}$ et al., 2008; Stefanko et al., 2009; Intlekofer et al., 2013; Yoo et al., 2015). These neuroprotective effects of sodium butyrate potentially occur through the inhibition of histone deacetylase (HDAC), which is known to prevent the transcription of BDNF and GDNF (Wu et al., 2008). Butyrate also has antiinflammatory actions in the gut and brain by preventing the induction of the inflammatory cytokine TNF $\alpha$ by the endotoxin lipopolysaccharide (LPS) via the suppression of nuclear factor $\kappa \mathrm{B}$ (Segain et al., 2000). Taken together, SCFAs produced by gut bacteria (whose levels are reduced by WD consumption; Berger et al., 2014) may affect brain health directly via HDAC inhibition in the brain, or indirectly by reducing systemic inflammation in the gut. Butyrate has also been shown to stabilize hypoxiainducible factor (HIF; Kelly et al., 2015), which is critical for maintaining gut barrier integrity and protecting against the influx of potentially harmful toxins, a topic discussed in more depth below.

\section{GUT AND NEUROVASCULAR BARRIER INTEGRITY}

Emerging research is revealing that gut microbiota have potent effects on gut permeability (Cani et al., 2007, 2008, 2009; Lam et al., 2012; Pendyala et al., 2012; Tulstrup et al., 2015; Maffeis et al., 2016; Mokkala et al., 2016; Müller et al., 2016) and bloodbrain barrier integrity (Braniste et al., 2014), both of which are negatively impacted by WD intake and proposed mechanisms underlying WD induced cognitive impairments (Kanoski et al., 2010; Davidson et al., 2012; Hsu and Kanoski, 2014; Ouyang et al., 2014; Hargrave et al., 2016; Stranahan et al., 2016). Several studies discussed here support a causal relationship between WD-mediated gut microbiota alterations, the gut/neurovascular barrier integrity, and hippocampal function.

The gut barrier consists of a specialized, semi-permeable mucosal, and epithelial cell layers that are reinforced by tight junction proteins. Among other functions, this barrier serves to regulate nutrient and water entry and prevents the entry of harmful compounds into extra-luminal tissues (for review see Turner, 2009). WD consumption impairs gut permeability, which in turn allows for the influx of adverse substances and may ultimately contribute to the development of metabolic disorders, and cognitive dysfunction. For example, in humans there is a strong association between obesity, gut permeability, and systemic inflammation (Maffeis et al., 2016; Rainone et al., 2016). In rodents, WD intake decreases levels of the tight junction protein ZO-1 and transepithelial resistance in the proximal colon, both markers of gut barrier dysfunction (Lam et al., 2012). A compromised gut barrier makes the intestinal tract potentially vulnerable to the gram-negative bacteria-derived LPS, which upon excess entry into circulation promotes endotoxemia and systemic inflammation (Griffiths et al., 2004; Cani et al., 2007, 2008; Tsukumo et al., 2007). Indeed, mice maintained on a WD for 4 weeks exhibit a $\sim$ three-fold increase in circulating LPS levels with concurrent increased intestinal permeability, as reflected by reduced mRNA expression of tight junction proteins $\mathrm{ZO}-1$ and occludin, as well as elevated plasma levels of a gavaged fluorescent molecule (FITC-dextran) that is typically unable to cross the gut barrier (Cani et al., 2008). This study further demonstrated that antibiotic treatment attenuated obesityinduced endotoxemia, thus providing potential physiological links between WD, the gut microbiome, and gut barrier integrity (Cani et al., 2008).

The blood-brain barrier (BBB) consists of a structural complex of endothelial cells, pericytes, and glial cells that encompass microvasculature networks within the central nervous system. It serves as a critical regulator for the entry of blood-derived nutrients and compounds required for healthy brain function, while simultaneously precluding the entry of potentially harmful blood-derived toxins. Importantly, WD intake is associated with $\mathrm{BBB}$ damage, which may be causally related to WDinduced cognitive dysfunction (Kanoski et al., 2010; Freeman et al., 2011; Davidson et al., 2012; Freeman and Granholm, 2012; Pallebage-Gamarallage et al., 2012; Hargrave et al., 2016; Stranahan et al., 2016). For example, in a study from Kanoski et al. (2010), rats maintained on a WD for 90 days exhibited a 
leaky $\mathrm{BBB}$ in the hippocampus and reduced mRNA expression of the tight junction proteins claudin- 5 and claudin-12. These negative BBB outcomes were accompanied by impairments in hippocampal-dependent memory tasks, suggesting that WDinduced $\mathrm{BBB}$ damage may be causally related to cognitive deficits. Davidson and colleagues extended this work (Davidson et al., 2012) by showing that rats prone to obesity are more susceptible to WD-induced BBB damage and cognitive impairment compared to obesity resistant animals. Moreover, the magnitude of BBB damage and memory impairment depends on both obesity susceptibility and the duration of WD exposure (Hargrave et al., 2016). Collectively, these data provide strong evidence linking WD intake, BBB integrity, and hippocampal dysfunction.

Braniste et al. (2014) illuminate an association between gut microbiome perturbation and impaired BBB integrity. Infrared-labeled immunoglobulin antibody (IgG2b; normally precluded from brain parenchyma) injected into pregnant germ-free (microbiome-free) mouse dams was abundant in the brains of their mouse embryos compared to the embryos of pathogen-free (microbiome-intact) dams, suggesting that maternal gut microbiome has strong influences on the offspring's BBB integrity. Moreover, compared to adult pathogen-free mice, adult germ-free mice exhibited impaired BBB integrity evidenced by increased brain uptake of tail-vein injected radio labeled ligand [11C] raclopride and increased presence of Evans blue dye (normally precluded from BBB penetration) in brain parenchyma following circulatory injections. Interestingly, transfer of pathogen-free fecal matter to germ-free mice attenuated BBB damage, reflected by the increased expression of tight junction proteins. These data implicate an important role for the gut microbiome in regulating $\mathrm{BBB}$ integrity. Whether gut microbiome perturbations associated with WD consumption are causally related to WD-associated barrier dysfunction and memory impairments require further investigation.

\section{NEUROINFLAMMATION}

Rodent studies have consistently shown that chronic consumption of a WD elevates levels of neuroinflammatory markers, which are associated with impaired cognition (Pistell et al., 2010; Puig et al., 2012; Herculano et al., 2013; Camer et al., 2015; Hsu et al., 2015; Ledreux et al., 2016). In conjunction with cognitive impairments, rats fed a WD have increased neuroinflammation in both the hippocampus (Puig et al., 2012; Herculano et al., 2013; Hsu et al., 2015; Ledreux et al., 2016) and in the cortex (Pistell et al., 2010; Camer et al., 2015). Moreover, clinical reports implicate a positive association between circulating inflammatory factors and cognitive decline in humans (Sweat et al., 2008; Sellbom and Gunstad, 2012). A WD may impact neuroinflammation and cognitive outcomes in part via altering levels of gut bacteria, as certain gut bacteria stimulate the innate immune system to elevate inflammatory cytokines in the brain (for review see Sankowski et al., 2015).

One putative mechanism through which WD influences gut bacteria and imparts hippocampal dysfunction involves elevated levels of endotoxin and accompanying inflammatory cytokines. WD consumption elevates levels of inflammatory endotoxins such as LPS (Cani et al., 2007; Amar et al., 2008; Bruce-Keller et al., 2015), and elevated levels of microbiomederived LPS in circulation stimulate inflammatory pathways. Additionally, gut microbiota directly stimulate the production of the proinflammatory cytokines IL-1 $\beta$ and TNF $\alpha$ (Heumann et al., 1994), which have been shown to impair hippocampal-dependent memories in rodents (Rachal Pugh et al., 2001; Goshen et al., 2007; Hein et al., 2010).

In addition to elevating levels of endotoxin producing bacteria, a WD may affect neuroinflammation by reducing levels of anti-inflammatory commensal gut bacteria. BruceKeller et al. (2015) demonstrated that WD fecal/cecal transplant recipient mice were normal weight, yet had elevated levels of endotoxin and neuroinflammatory markers accompanied by impaired cognitive function. The bacterial species A. muciniphila was reduced by the diet (Bruce-Keller et al., 2015); a species that is negatively associated with inflammation (Schneeberger et al., 2015). Similarly, anti-inflammatory Lactobacilli are reduced by WD factors (Jena et al., 2014; Lecomte et al., 2015) and supplementation with Lactobacillus helveticus prevents spatial memory impairment in WD-fed mice lacking the anti-inflammatory cytokine IL-10 (Ohland et al., 2013). One method by which members of the Lactobacilli family and other commensal bacteria may reduce systemic inflammation is by improving insulin sensitivity (Simon et al., 2015), a concept reviewed in the following section.

\section{INSULIN}

Insulin, produced in pancreatic beta cells and released in response to conditioned cephalic cues or circulating metabolites, crosses the $\mathrm{BBB}$ via a saturable transporter, and insulin receptors are present in neurons and primarily localized to synapses (Zhao and Alkon, 2001). Levels of insulin receptor are particularly concentrated in the hippocampus (Havrankova et al., 1978) where insulin signaling improves cognitive function and neuronal plasticity (Biessels et al., 1998; Kamal et al., 2000; Grillo et al., 2009, 2015; Biessels and Reagan, 2015). WDinduced peripheral insulin resistance is associated with impaired cognitive function and synaptic plasticity in rats (Elias et al., 1997; Grodstein et al., 2001; Hiltunen et al., 2001; Yaffe et al., 2004; Stranahan et al., 2008; Pavlik et al., 2013; Gao et al., 2015) and the risk for developing Alzheimer's disease or dementia in humans (Ott et al., 1999; Arvanitakis et al., 2004; Luchsinger et al., 2004; Cukierman et al., 2005; Rönnemaa et al., 2008).

Insulin impacts neurological health via multiple mechanisms. One of the functions of CNS insulin is to phosphorylate $\alpha$ amino-3-hydroxy-5-methyl-4- isoxazolepropionic acid (AMPA) receptors, which leads to increased hippocampal long-term potentiation (LTP; Adzovic and Domenici, 2014). Another mechanism through which insulin may improve cognitive function is by reducing neuroinflammation. For example, intracerebroventricular injection of insulin attenuates LPSinduced elevations in IL-1 $\beta$ and improves spatial memory impairment in young rats (Adzovic et al., 2015). Insulin has a 
similar anti-inflammatory function in the periphery, where it has been shown to reduce the systemic inflammatory response to endotoxin (Jeschke et al., 2004). Thus, if gut microbiota impact cognitive function in part via the modulation of inflammatory responses, or by elevating levels of peripheral or central endotoxin, then insulin may provide protection against gut microbiome-mediated cognitive dysfunction in insulin sensitive individuals. Given that long-term exposure to ad libitum fructose $(15 \% \mathrm{w} / \mathrm{v}$ in water) impairs insulin receptor function in the hippocampus and reduced hippocampusdependent spatial memory (Agrawal et al., 2016), a harmful synergy may occur through which WD intake both increases neuroinflammation (as reviewed above) and impairs central insulin sensitivity, thereby preventing insulin from attenuating inflammatory responses and associated adverse neuronal outcomes.

Recent findings directly link gut microbiota and $\mathrm{CNS} /$ peripheral insulin sensitivity. In humans, an intraduodenal microbiome transfer from lean healthy donors to individuals with impaired insulin sensitivity improves insulin sensitivity in the recipients (Vrieze et al., 2012). Interestingly, transferring the fecal microbiome from obese or lean discordant human twin pairs to mice resulted in impaired glucose metabolism in the mouse if the transfer came from an obese twin (Ridaura et al., 2013). In mice, antiobiotic-induced microbiome depletion improves peripheral insulin sensitivity caused by a WD (Suárez-Zamorano et al., 2015). The effect of gut microbiota on peripheral insulin sensitivity begins at the level of the intestinal mucosa, as WD-induced insulin resistance is prevented by blocking live intestinal bacteria from translocating into the blood and tissues where they generate an inflammatory response (Amar et al., 2011). Bacterial translocation preceded WD-induced insulin resistance, and required functioning Nod1 and CD14 receptors, which bind to gram-negative bacteria. Furthermore, the translocation of bacteria and the insulin resistance were preventable when animals were treated with the probiotic Bifidobacterium Animalis, which specifically prevents translocation of Enterobacteriaceae (Amar et al., 2011). Taken together, commensal bacteria may alter peripheral insulin sensitivity in a mechanism that likely involves inflammatory signaling and/or bacterial translocation from the gut into the periphery.

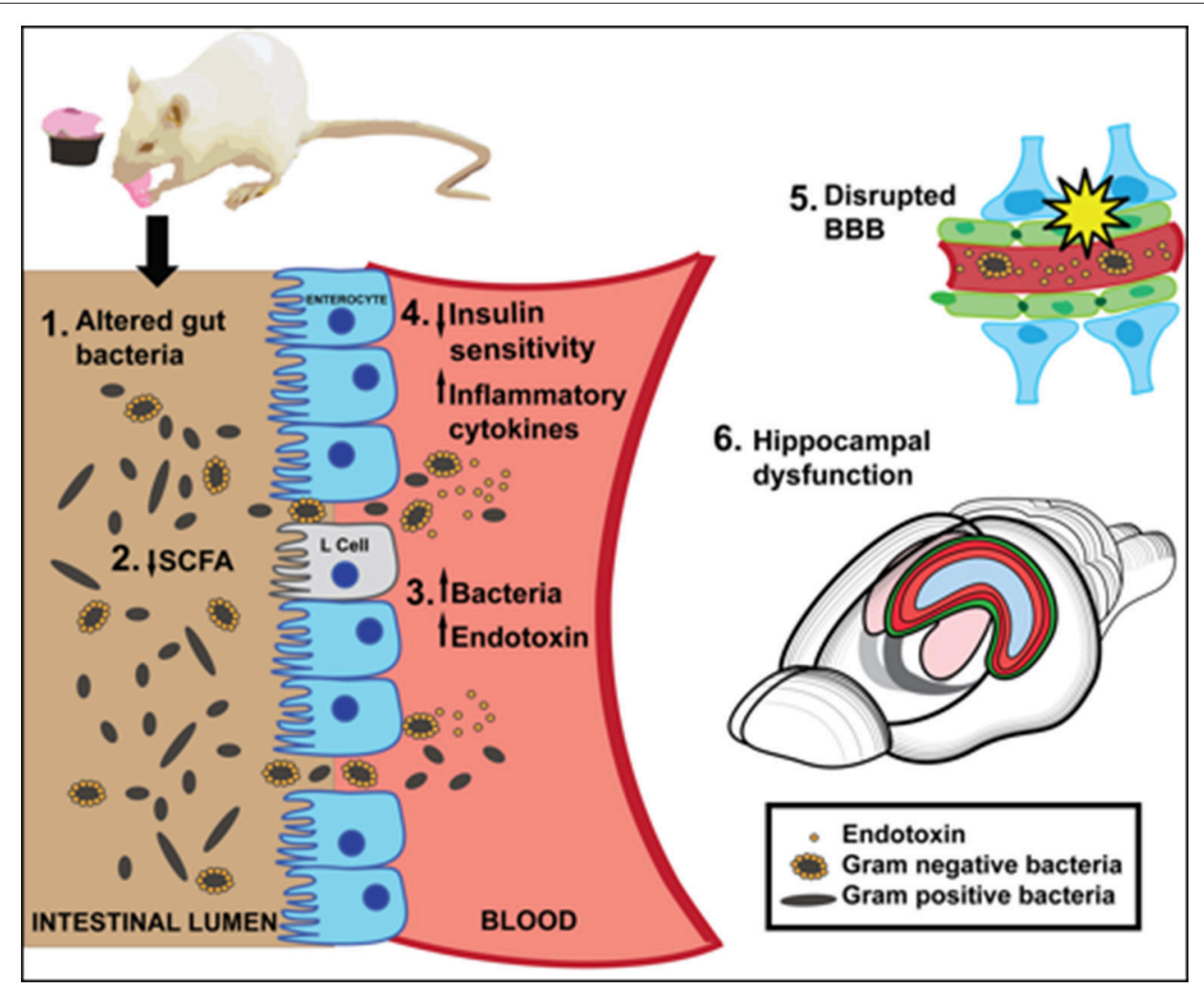

FIGURE 1 | A summary of putative mechanisms linking Western Diet (WD) consumption, the gut microbiome, and cognitive dysfunction. [1] A high fat/high sugar WD diet alters gut bacteria [2] WD reduces short chain fatty acids (SCFA), which may impair neuroprotection or anti-inflammatory effects in the gut. SCFAs affect insulin signaling by stimulating $L$ cell production of GLP-1. [3] WD may impair intestinal barrier and promote translocation of endotoxin-producing gram negative bacteria into the blood. [4] Inflammatory cytokines and/or reduced insulin sensitivity caused by WD-induced gut bacteria may negatively affect hippocampal function and memory. [5] A WD impairs BBB integrity, which may be caused in part by altered gut microbiota. [6] WD consumption significantly impairs hippocampal dependent learning and memory. 
Whether consuming a WD promotes cognitive dysfunction through modifying gut microbiota that impair insulin receptor signaling remains to be determined. However, one study revealed that probiotic treatment normalized spatial memory deficits and improved hippocampal LTP in a streptozocin rat model of diabetes (Davari et al., 2013), suggesting that gut microbiota can improve cognitive dysfunction due to reduced insulin production. Interestingly, evidence suggests that commensal gut bacteria may enhance insulin sensitivity and cognitive function by modulating the production and/or secretion of the incretin hormones glucagon-like peptide-1 (GLP-1). SCFAs, such as butyrate, produced by commensal gut bacteria act on $\mathrm{G}$ protein coupled receptors to stimulate GLP-1 secretion (Tolhurst et al., 2012). Hwang and collegues showed that antibiotics reduced the proportion of Bacteriodetes and Firmicutes in mice, which resulted in attenuated pancreatic islet hypertrophy and improved insulin and glucose tolerance through a GLP-1 signaling pathway (Hwang et al., 2015). Importantly, GLP-1 signaling promotes hippocampal neural plasticity and improved memory function (During et al., 2003; McClean et al., 2010; Li et al., 2012). Taken together, these collective data suggest that commensal gut bacteria modulate insulin sensitivity via multiple mechanisms, which may be related to WD-induced hippocampal dysfunction.

\section{CONCLUDING REMARKS}

Several neurobiological mechanisms link WD consumption with gut microbiome alterations that potentially contribute to WD-mediated cognitive dysfunction, including reduced SCFA production, compromised barrier integrity, neuroinflammation, and peripheral and/or central insulin receptor resistance (Figure 1). Consuming a WD promotes endotoxemia, which is linked with memory impairment, either via translocation of gram-negative bacteria into circulation, and/or by impairing

\section{REFERENCES}

Adzovic, L., and Domenici, L. (2014). Insulin induces phosphorylation of the AMPA receptor subunit GluR1, reversed by ZIP, and over-expression of Protein Kinase M zeta, reversed by amyloid beta. J. Neurochem. 131, 582-587. doi: $10.1111 /$ jnc. 12947

Adzovic, L., Lynn, A. E., D’Angelo, H. M., Crockett, A. M., Kaercher, R. M., Royer, S. E., et al. (2015). Insulin improves memory and reduces chronic neuroinflammation in the hippocampus of young but not aged brains. J. Neuroinflammation 12, 63. doi: 10.1186/s12974-0150282-z

Agrawal, R., Noble, E., Vergnes, L., Ying, Z., Reue, K., and Gomez-Pinilla, F. (2016). Dietary fructose aggravates the pathobiology of traumatic brain injury by influencing energy homeostasis and plasticity. J. Cereb. Blood Flow Metab. 36, 941-953. doi: 10.1177/0271678X15606719

Ahluwalia, V., Betrapally, N. S., Hylemon, P. B., White, M. B., Gillevet, P. M., Unser, A. B., et al. (2016). Impaired gut-liver-brain axis in patients with cirrhosis. Sci. Rep. 6:26800. doi: 10.1038/srep26800

Amar, J., Burcelin, R., Ruidavets, J. B., Cani, P. D., Fauvel, J., Alessi, M. C., et al. (2008). Energy intake is associated with endotoxemia in apparently healthy men. Am. J. Clin. Nutr. 87, 1219-1223.

Amar, J., Chabo, C., Waget, A., Klopp, P., Vachoux, C., Bermúdez-Humarán, L. G., et al. (2011). Intestinal mucosal adherence and translocation of commensal bacteria at the early onset of type 2 diabetes: molecular the permeability of the gut barrier. Both gut microbiota and WD intake have been shown to impair the permeability of the $\mathrm{BBB}$, however mechanistic studies linking WD intake, $\mathrm{BBB}$ integrity, and the gut microbiome are required. WDassociated microbiota alterations impair peripheral insulin sensitivity, which is strongly linked with central insulin resistance and hippocampal dysfunction. In addition, insulin protects against peripheral inflammatory responses to endotoxin, and may prevent the deleterious effects imparted by WDmediated bacterial production of endotoxins in insulin sensitive individuals.

Overall we present multiple pathways through which WDinduced microbiome alterations can impact neurocognitive function. Mechanistic studies examining these putative gut brain axis pathways may facilitate the development of therapies that target the microbiome (probiotics, prebiotics, antibiotics, or microbiota transfer) to treat neurobiological and cognitive dysfunction associated with WD intake and associated metabolic disorders.

\section{AUTHOR CONTRIBUTIONS}

All three authors contributed to the idea for the manuscript. EN and TH wrote and edited the manuscript. SK edited the manuscript, provided vital input to shape the manuscript, and contributed to the writing. All three authors approved the final manuscript.

\section{FUNDING}

This work was supported by grant number DK104897 from the National Institute of Diabetes and Digestive and Kidney Diseases and also by the University of Southern California Diabetes and Obesity Research Institute (Awarded to SK). mechanisms and probiotic treatment. EMBO Mol. Med. 3, 559-572. doi: 10.1002/emmm.201100159

Arvanitakis, Z., Wilson, R. S., Bienias, J. L., Evans, D. A., and Bennett, D. A. (2004). Diabetes mellitus and risk of Alzheimer disease and decline in cognitive function. Arch. Neurol. 61, 661-666. doi: 10.1001/archneur.61.5.661

Bäckhed, F., Ley, R. E., Sonnenburg, J. L., Peterson, D. A., and Gordon, J. I. (2005). Host-bacterial mutualism in the human intestine. Science 307, 1915-1920. doi: $10.1126 /$ science. 1104816

Bajaj, J. S., Ridlon, J. M., Hylemon, P. B., Thacker, L. R., Heuman, D. M., Smith, S., et al. (2012). Linkage of gut microbiome with cognition in hepatic encephalopathy. Am. J. Physiol. Gastrointest. Liver Physiol. 302, G168-G175. doi: 10.1152/ajpgi.00190.2011

Baym, C. L., Khan, N. A., Monti, J. M., Raine, L. B., Drollette, E. S., Moore, R. D., et al. (2014). Dietary lipids are differentially associated with hippocampaldependent relational memory in prepubescent children. Am. J. Clin. Nutr. 99, 1026-1032. doi: 10.3945/ajcn.113.079624

Beilharz, J. E., Kaakoush, N. O., Maniam, J., and Morris, M. J. (2016a). The effect of short-term exposure to energy-matched diets enriched in fat or sugar on memory, gut microbiota and markers of brain inflammation and plasticity. Brain Behav. Immun. 57, 304-313. doi: 10.1016/j.bbi.2016.07.151

Beilharz, J. E., Maniam, J., and Morris, M. J. (2014). Short exposure to a diet rich in both fat and sugar or sugar alone impairs place, but not object recognition memory in rats. Brain Behav. Immun. 37, 134-141. doi: 10.1016/j.bbi.2013.11.016 
Beilharz, J. E., Maniam, J., and Morris, M. J. (2015). Diet-induced cognitive deficits: the role of fat and sugar, potential mechanisms and nutritional interventions. Nutrients 7, 6719-6738. doi: 10.3390/nu7085307

Beilharz, J. E., Maniam, J., and Morris, M. J. (2016b). Short-term exposure to a diet high in fat and sugar, or liquid sugar, selectively impairs hippocampaldependent memory, with differential impacts on inflammation. Behav. Brain Res. 306, 1-7. doi: 10.1016/j.bbr.2016.03.018

Bercik, P., Denou, E., Collins, J., Jackson, W., Lu, J., Jury, J., et al. (2011). The intestinal microbiota affect central levels of brain-derived neurotropic factor and behavior in mice. Gastroenterology 141, 599-609, 609.e1-3. doi: 10.1053/j.gastro.2011.04.052

Berger, K., Falck, P., Linninge, C., Nilsson, U., Axling, U., Grey, C., et al. (2014). Cereal byproducts have prebiotic potential in mice fed a high-fat diet. J. Agric. Food Chem. 62, 8169-8178. doi: 10.1021/j5502343v

Biessels, G. J., and Reagan, L. P. (2015). Hippocampal insulin resistance and cognitive dysfunction. Nat. Rev. Neurosci. 16, 660-671. doi: 10.1038/nrn4019

Biessels, G. J., Kamal, A., Urban, I. J., Spruijt, B. M., Erkelens, D. W., and Gispen, W. H. (1998). Water maze learning and hippocampal synaptic plasticity in streptozotocin-diabetic rats: effects of insulin treatment. Brain Res. 800, $125-135$.

Braniste, V., Al-Asmakh, M., Kowal, C., Anuar, F., Abbaspour, A., Tóth, M., et al. (2014). The gut microbiota influences blood-brain barrier permeability in mice. Sci. Transl. Med. 6:263ra158. doi: 10.1126/scitranslmed.3009759

Bruce-Keller, A. J., Salbaum, J. M., Luo, M., Blanchard, E. IV, Taylor, C. M., Welsh, D. A., et al. (2015). Obese-type gut microbiota induce neurobehavioral changes in the absence of obesity. Biol. Psychiatry 77, 607-615. doi: 10.1016/j.biopsych.2014.07.012

Camer, D., Yu, Y., Szabo, A., Fernandez, F., Dinh, C. H., and Huang, X. F. (2015). Bardoxolone methyl prevents high-fat diet-induced alterations in prefrontal cortex signalling molecules involved in recognition memory. Prog. Neuropsychopharmacol. Biol. Psychiatry 59, 68-75. doi: 10.1016/j.pnpbp.2015.01.00

Cani, P. D., Amar, J., Iglesias, M. A., Poggi, M., Knauf, C., Bastelica, D., et al. (2007). Metabolic endotoxemia initiates obesity and insulin resistance. Diabetes 56, 1761-1772. doi: 10.2337/db06-1491

Cani, P. D., Bibiloni, R., Knauf, C., Waget, A., Neyrinck, A. M., Delzenne, N. M., et al. (2008). Changes in gut microbiota control metabolic endotoxemiainduced inflammation in high-fat diet-induced obesity and diabetes in mice. Diabetes 57, 1470-1481. doi: 10.2337/db07-1403

Cani, P. D., Possemiers, S. T., Van de Wiele, T., Guiot, Y., Everard, A., Rottier, O., et al. (2009). Changes in gut microbiota control inflammation in obese mice through a mechanism involving GLP-2-driven improvement of gut permeability. Gut 58, 1091-1103. doi: 10.1136/gut.2008.165886

Cukierman, T., Gerstein, H. C., and Williamson, J. D. (2005). Cognitive decline and dementia in diabetes-systematic overview of prospective observational studies. Diabetologia 48, 2460-2469. doi: 10.1007/s00125-005-0023-4

Daniel, H., Gholami, A. M., Berry, D., Desmarchelier, C., Hahne, H., Loh, G., et al. (2014). High-fat diet alters gut microbiota physiology in mice. ISME J. 8, 295-308. doi: 10.1038/ismej.2013.155

Davari, S., Talaei, S. A., Alaei, H., and Salami, M. (2013). Probiotics treatment improves diabetes-induced impairment of synaptic activity and cognitive function: behavioral and electrophysiological proofs for microbiome-gut-brain axis. Neuroscience 240, 287-296. doi: 10.1016/j.neuroscience.2013.02.055

David, L. A., Maurice, C. F., Carmody, R. N., Gootenberg, D. B., Button, J. E., Wolfe, B. E., et al. (2014). Diet rapidly and reproducibly alters the human gut microbiome. Nature, 505, 559-563. doi: 10.1038/nature 12820

Davidson, T. L., Monnot, A., Neal, A. U., Martin, A. A., Horton, J. J., and Zheng, W. (2012). The effects of a high-energy diet on hippocampaldependent discrimination performance and blood-brain barrier integrity differ for diet-induced obese and diet-resistant rats. Physiol. Behav. 107, 26-33. doi: 10.1016/j.physbeh.2012.05.015

Davidson, T. L., Sample, C. H., and Swithers, S. E. (2014). An application of Pavlovian principles to the problems of obesity and cognitive decline. Neurobiol. Learn. Mem. 108, 172-184. doi: 10.1016/j.nlm.2013.07.014

de La Serre, C. B., Ellis, C. L., Lee, J., Hartman, A. L., Rutledge, J. C., and Raybould, H. E. (2010). Propensity to high-fat diet-induced obesity in rats is associated with changes in the gut microbiota and gut inflammation. Am. J. Physiol. Gastrointest. Liver Physiol. 299, G440-G448. doi: 10.1152/ajpgi.00098.2010
Derrien, M., Belzer, C., and de Vos, W. M. (2016). Akkermansia muciniphila and its role in regulating host functions. Microbial pathogenesis. doi: 10.1016/j.micpath.2016.02.005. [Epub ahead of print].

Desbonnet, L., Clarke, G., Traplin, A., O’Sullivan, O., Crispie, F., Moloney, R. D., et al. (2015). Gut microbiota depletion from early adolescence in mice: implications for brain and behaviour. Brain Behav. Immun. 48, 165-173. doi: 10.1016/j.bbi.2015.04.004

Devkota, S., Wang, Y., Musch, M. W., Leone, V., Fehlner-Peach, H., Nadimpalli, A., et al. (2012). Dietary-fat-induced taurocholic acid promotes pathobiont expansion and colitis in Il10-/- mice. Nature 487, 104-108. doi: 10.1038 /nature11225

During, M. J., Cao, L., Zuzga, D. S., Francis, J. S., Fitzsimons, H. L., Jiao, X., et al. (2003). Glucagon-like peptide-1 receptor is involved in learning and neuroprotection. Nat. Med. 9, 1173-1179. doi: 10.1038/nm919

Elias, P. K., Elias, M. F., D’Agostino, R. B., Cupples, L. A., Wilson, P. W., Silbershatz, H., et al. (1997). NIDDM and blood pressure as risk factors for poor cognitive performance. The Framingham Study. Diabetes Care 20, 1388-1395. doi: $10.2337 /$ diacare.20.9.1388

Francis, H. M., and Stevenson, R. J. (2011). Higher reported saturated fat and refined sugar intake is associated with reduced hippocampal-dependent memory and sensitivity to interoceptive signals. Behav. Neurosci. 125, 943-955. doi: $10.1037 / \mathrm{a} 0025998$

Francis, H., and Stevenson, R. (2013). The longer-term impacts of Western diet on human cognition and the brain. Appetite 63, 119-128. doi: 10.1016/j.appet.2012.12.018

Freeman, L. R., and Granholm, A. C. (2012). Vascular changes in rat hippocampus following a high saturated fat and cholesterol diet. J. Cereb. Blood Flow Metab. 32, 643-653. doi: 10.1038/jcbfm.2011.168

Freeman, L. R., Haley-Zitlin, V., Stevens, C., and Granholm, A. C. (2011). Diet-induced effects on neuronal and glial elements in the middle-aged rat hippocampus. Nutr. Neurosci. 14, 32-44. doi: 10.1179/174313211X12966635733358

Fröhlich, E. E., Farzi, A., Mayerhofer, R., Reichmann, F., Jacan, A., Wagner, B., et al. (2016). Cognitive impairment by antibiotic-induced gut dysbiosis: analysis of gut microbiota-brain communication. Brain Behav. Immun. 56, 140-155. doi: 10.1016/j.bbi.2016.02.020

Gao, Y., Xiao, Y., Miao, R., Zhao, J., Zhang, W., Huang, G., et al. (2015). The characteristic of cognitive function in Type 2 diabetes mellitus. Diabetes Res. Clin. Pract. 109, 299-305. doi: 10.1016/j.diabres.2015.05.019

Gareau, M. G., Wine, E., Rodrigues, D. M., Cho, J. H., Whary, M. T., Philpott, D. J., et al. (2011). Bacterial infection causes stress-induced memory dysfunction in mice. Gut 60, 307-317. doi: 10.1136/gut.2009.202515

Goshen, I., Kreisel, T., Ounallah-Saad, H., Renbaum, P., Zalzstein, Y., BenHur, T., et al. (2007). A dual role for interleukin-1 in hippocampaldependent memory processes. Psychoneuroendocrinology 32, 1106-1115. doi: 10.1016/j.psyneuen.2007.09.004

Griffiths, E. A., Duffy, L. C., Schanbacher, F. L., Qiao, H., Dryja, D., Leavens, A., et al. (2004). In vivo effects of bifidobacteria and lactoferrin on gut endotoxin concentration and mucosal immunity in Balb/c mice. Dig. Dis. Sci. 49, 579-589. doi: 10.1023/B:DDAS.0000026302.92898.ae

Grillo, C. A., Piroli, G. G., Hendry, R. M., and Reagan, L. P. (2009). Insulin-stimulated translocation of GLUT4 to the plasma membrane in rat hippocampus is PI3-kinase dependent. Brain Res. 1296, 35-45. doi: 10.1016/j.brainres.2009.08.005

Grillo, C. A., Piroli, G. G., Lawrence, R. C., Wrighten, S. A., Green, A. J., Wilson, S. P., et al. (2015). Hippocampal insulin resistance impairs spatial learning and synaptic plasticity. Diabetes 64, 3927-3936. doi: 10.2337/db15-0596

Grodstein, F., Chen, J., Wilson, R. S., and Manson, J. E. (2001). Nurses' Health, Type 2 diabetes and cognitive function in community-dwelling elderly women. Diabetes Care 24, 1060-1065. doi: 10.2337/diacare.24.6.1060

Hargrave, S. L., Davidson, T. L., Zheng, W., and Kinzig, K. P. (2016). Western diets induce blood-brain barrier leakage and alter spatial strategies in rats. Behav. Neurosci. 130, 123-135. doi: 10.1037/bne0000110

Havrankova, J., Schmechel, D., Roth, J., and Brownstein, M. (1978). Identification of insulin in rat brain. Proc. Natl. Acad. Sci. U.S.A. 75, 5737-5741. doi: 10.1073/pnas.75.11.5737

Hein, A. M., Stasko, M. R., Matousek, S. B., Scott-McKean, Maier, J. J., Maier, S. F., Olschowka, J. A., et al. (2010). Sustained hippocampal IL-1beta overexpression 
impairs contextual and spatial memory in transgenic mice. Brain Behav. Immun. 24, 243-253. doi: 10.1016/j.bbi.2009.10.002

Herculano, B., Tamura, M., Ohba, A., Shimatani, M., Kutsuna, N., and Hisatsune, T. (2013). beta-alanyl-L-histidine rescues cognitive deficits caused by feeding a high fat diet in a transgenic mouse model of Alzheimer's disease. J. Alzheimers. Dis. 33, 983-997. doi: 10.3233/JAD-2012-121324

Heumann, D., Barras, C., Severin, A., Glauser, M. P., and Tomasz, A. (1994). Gram-positive cell walls stimulate synthesis of tumor necrosis factor alpha and interleukin- 6 by human monocytes. Infect. Immun. 62, 2715-2721.

Hildebrandt, M. A., Hoffmann, C., Sherrill-Mix, S. A., Keilbaugh, S. A., Hamady, M., Chen, Y. Y., et al. (2009). High-fat diet determines the composition of the murine gut microbiome independently of obesity. Gastroenterology 137, 1716-24.e1-2. doi: 10.1053/j.gastro.2009.08.042

Hiltunen, L. A., Keinänen-Kiukaanniemi, S. M., and Lääräa, E. M. (2001). Glucose tolerance and cognitive impairment in an elderly population. Public Health 115, 197-200. doi: 10.1016/S0033-3506(01)00443-7

Hsiao, E. Y., McBride, S. W., Hsien, S., Sharon, G., Hyde, E. R., McCue, T., et al. (2013). Microbiota modulate behavioral and physiological abnormalities associated with neurodevelopmental disorders. Cell 155, 1451-1463. doi: 10.1016/j.cell.2013.11.024

Hsu, T. M., and Kanoski, S. E. (2014). Blood-brain barrier disruption: mechanistic links between Western diet consumption and dementia. Front. Aging Neurosci. 6:88. doi: 10.3389/fnagi.2014.00088

Hsu, T. M., Konanur, V. R., Taing, L., Usui, R., Kayser, B. D., Goran, M. I., et al. (2015). Effects of sucrose and high fructose corn syrup consumption on spatial memory function and hippocampal neuroinflammation in adolescent rats. Hippocampus 25, 227-239. doi: 10.1002/hipo.22368

Hwang, I., Park, Y. J., Kim, Y. R., Kim, Y. N., Ka, S., Lee, H. Y., et al. (2015). Alteration of gut microbiota by vancomycin and bacitracin improves insulin resistance via glucagon-like peptide 1 in diet-induced obesity. FASEB J. 29, 2397-2411. doi: 10.1096/fj.14-265983

Intlekofer, K. A., Berchtold, N. C., Malvaez, M., Carlos, A. J., McQuown, S. C., Cunningham, M. J., et al. (2013). Exercise and sodium butyrate transform a subthreshold learning event into long-term memory via a brainderived neurotrophic factor-dependent mechanism. Neuropsychopharmacology 38, 2027-2034. doi: 10.1038/npp.2013.104

Jagust, W., Harvey, D., Mungas, D., and Haan, M. (2005). Central obesity and the aging brain. Arch. Neurol. 62, 1545-1548. doi: 10.1001/archneur.62.10.1545

Jena, P. K., Singh, S., Prajapati, B., Nareshkumar, G., Mehta, T., and Seshadri, S. (2014). Impact of targeted specific antibiotic delivery for gut microbiota modulation on high-fructose-fed rats. Appl. Biochem. Biotechnol. 172, 3810-3826. doi: 10.1007/s12010-014-0772-y

Jeschke, M. G., Klein, D., Bolder, U., and Einspanier, R. (2004). Insulin attenuates the systemic inflammatory response in endotoxemic rats. Endocrinology 145, 4084-4093. doi: 10.1210/en.2004-0592

Jia, W., Whitehead, R. N., Griffiths, L., Dawson, C., Bai, H., Waring, R. H., et al. (2012). Diversity and distribution of sulphate-reducing bacteria in human faeces from healthy subjects and patients with inflammatory bowel disease. FEMS Immunol. Med. Microbiol. 65, 55-68. doi: 10.1111/j.1574-695X.2012.00935.X

Kalmijn, S., van Boxtel, M. P., Ocké, M., Verschuren, W. M., Kromhout, D., and Launer, L. J. (2004). Dietary intake of fatty acids and fish in relation to cognitive performance at middle age. Neurology 62, 275-280. doi: 10.1212/01.WNL.0000103860.75218.A5

Kamal, A., Biessels, G. J., Duis, S. E., and Gispen, W. H. (2000). Learning and hippocampal synaptic plasticity in streptozotocin-diabetic rats: interaction of diabetes and ageing. Diabetologia 43, 500-506. doi: 10.1007/s001250051335

Kanoski, S. E., and Davidson, T. L. (2010). Different patterns of memory impairments accompany short- and longer-term maintenance on a high-energy diet. J. Exp. Psychol. Anim. Behav. Process. 36, 313-319. doi: 10.1037/a0017228

Kanoski, S. E., and Davidson, T. L. (2011). Western diet consumption and cognitive impairment: links to hippocampal dysfunction and obesity. Physiol. Behav. 103, 59-68. doi: 10.1016/j.physbeh.2010.12.003

Kanoski, S. E., Meisel, R. L., Mullins, A. J., and Davidson, T. L. (2007). The effects of energy-rich diets on discrimination reversal learning and on BDNF in the hippocampus and prefrontal cortex of the rat. Behav. Brain Res. 182, 57-66. doi: 10.1016/j.bbr.2007.05.004
Kanoski, S. E., Zhang, Y., Zheng, W., and Davidson, T. L. (2010). The effects of a high-energy diet on hippocampal function and blood-brain barrier integrity in the rat. J. Alzheimers. Dis. 21, 207-219. doi: 10.3233/JAD-2010-091414

Kelly, C. J., Zheng, L., Campbell, E. L., Saeedi, B., Scholz, C. C., Bayless, A. J., et al. (2015). Crosstalk between microbiota-derived short-chain fatty acids and intestinal epithelial HIF augments tissue barrier function. Cell Host Microbe 17, 662-671. doi: 10.1016/j.chom.2015.03.005

Khan, N. A., Baym, C. L., Monti, J. M., Raine, L. B., Drollette, E. S., Scudder, M. R., et al. (2015a). Central adiposity is negatively associated with hippocampaldependent relational memory among overweight and obese children. J. Pediatr. 166, 302-8.e1. doi: 10.1016/j.jpeds.2014.10.008

Khan, N. A., Raine, L. B., Drollette, E. S., Scudder, M. R., and Hillman, C. H. (2015b). The relation of saturated fats and dietary cholesterol to childhood cognitive flexibility. Appetite 93, 51-56. doi: 10.1016/j.appet.2015.04.012

Kumar, A., Alrefai, W. A., Borthakur, A., and Dudeja, P. K. (2015). Lactobacillus acidophilus counteracts enteropathogenic E. coli-induced inhibition of butyrate uptake in intestinal epithelial cells. Am. J. Physiol. Gastrointest. Liver Physiol. 309, G602-G607. doi: 10.1152/ajpgi.00186.2015

Lam, Y. Y., Ha, C. W., Campbell, C. R., Mitchell, A. J., Dinudom, A., Oscarsson, J., et al. (2012). Increased gut permeability and microbiota change associate with mesenteric fat inflammation and metabolic dysfunction in diet-induced obese mice. PLoS ONE 7:e34233. doi: 10.1371/journal.pone.0034233

Lecomte, V., Kaakoush, N. O., Maloney, C. A., Raipuria, M., Huinao, K. D., Mitchell, H. M., et al. (2015). Changes in gut microbiota in rats fed a high fat diet correlate with obesity-associated metabolic parameters. PLoS ONE 10:e0126931. doi: 10.1371/journal.pone.0126931

Ledreux, A., Wang, X., Schultzberg, M., Granholm, A. C., and Freeman, L. R. (2016). Detrimental effects of a high fat/high cholesterol diet on memory and hippocampal markers in aged rats. Behav. Brain Res. 312, 294-304. doi: 10.1016/j.bbr.2016.06.012

Li, L., Zhang, Z. F., Holscher, C., Gao, C., Jiang, Y. H., and Liu, Y. Z. (2012). (Val(8)) glucagon-like peptide-1 prevents tau hyperphosphorylation, impairment of spatial learning and ultra-structural cellular damage induced by streptozotocin in rat brains. Eur. J. Pharmacol. 674, 280-286. doi: 10.1016/j.ejphar.2011.11.005

Li, X. L., Aou, S., Oomura, Y., Hori, N., Fukunaga, K., and Hori, T. (2002). Impairment of long-term potentiation and spatial memory in leptin receptor-deficient rodents. Neuroscience 113, 607-615. doi: 10.1016/S0306-4522(02)00162-8

Luchsinger, J. A., Tang, M. X., Shea, S., and Mayeux, R. (2004). Hyperinsulinemia and risk of Alzheimer disease. Neurology 63, 1187-1192. doi: 10.1212/01.WNL.0000140292.04932.87

Lupp, C., Robertson, M. L., Wickham, M. E., Sekirov, I., Champion, O. L., Gaynor, E. C., et al. (2007). Host-mediated inflammation disrupts the intestinal microbiota and promotes the overgrowth of Enterobacteriaceae. Cell Host Microbe 2:204. doi: 10.1016/j.chom.2007.06.010

MacFabe, D. F. (2012). Short-chain fatty acid fermentation products of the gut microbiome: implications in autism spectrum disorders. Microb. Ecol. Health Dis. 23, 1-24. doi: 10.3402/mehd.v23i0.19260

MacFarlane, G. T., and MacFarlane, S. (2011). Fermentation in the human large intestine: its physiologic consequences and the potential contribution of prebiotics. J. Clin. Gastroenterol. 45(Suppl.), S120-S127. doi: $10.1097 / \mathrm{mcg} .0 \mathrm{~b} 013 \mathrm{e} 31822 \mathrm{fecfe}$

Maffeis, C., Martina, A., Corradi, M., Quarella, S., Nori, N., Torriani, S., et al. (2016). Association between intestinal permeability and faecal microbiota composition in Italian children with beta cell autoimmunity at risk for type 1 diabetes. Diabetes Metab. Res. Rev. 32, 700-709. doi: 10.1002/dmrr.2790

Magnusson, K. R., Hauck, L., Jeffrey, B. M., Elias, V., Humphrey, A., Nath, R., et al. (2015). Relationships between diet-related changes in the gut microbiome and cognitive flexibility. Neuroscience 300, 128-140. doi: 10.1016/j.neuroscience.2015.05.016

McClean, P. L., Gault, V. A., Harriott, P., and Hölscher, C. (2010). Glucagonlike peptide-1 analogues enhance synaptic plasticity in the brain: a link between diabetes and Alzheimer's disease. Eur. J. Pharmacol. 630, 158-162. doi: 10.1016/j.ejphar.2009.12.023

Meng, Q., Ying, Z., Noble, E., Zhao, Y., Agrawal, R., Mikhail, A., et al. (2016). Systems nutrigenomics reveals brain gene networks linking metabolic and brain disorders. EBioMedicine 7, 157-166. doi: 10.1016/j.ebiom.2016.04.008 
Mokkala, K., Röytiö, H., Munukka, E., Pietilä, S., Ekblad, U., Rönnemaa, T., et al. (2016). Gut microbiota richness and composition and dietary intake of overweight pregnant women are related to serum zonulin concentration, a marker for intestinal permeability. J. Nutr. 146, 1694-1700. doi: 10.3945/jn.116.235358

Molteni, R., Barnard, R. J., Ying, Z., Roberts, C. K., and Gómez-Pinilla, F. (2002). A high-fat, refined sugar diet reduces hippocampal brain-derived neurotrophic factor, neuronal plasticity, and learning. Neuroscience 112, 803-814. doi: 10.1016/S0306-4522(02)00123-9

Molteni, R., Wu, A., Vaynman, S., Ying, Z., Barnard, R. J., and GómezPinilla, F. (2004). Exercise reverses the harmful effects of consumption of a high-fat diet on synaptic and behavioral plasticity associated to the action of brain-derived neurotrophic factor. Neuroscience 123, 429-440. doi: 10.1016/j.neuroscience.2003.09.020

Müller, V. M., Zietek, T., Rohm, F., Fiamoncini, J., Lagkouvardos, I., Haller, D., et al. (2016). Gut barrier impairment by high-fat diet in mice depends on housing conditions. Mol. Nutr. Food Res. 60, 897-908. doi: 10.1002/mnfr.201500775

Murray, A. J., Knight, N. S., Cochlin, L. E., McAleese, S., Deacon, R. M., Rawlins, J. N., et al. (2009). Deterioration of physical performance and cognitive function in rats with short-term high-fat feeding. FASEB J. 23, 4353-4360. doi: 10.1096/fj.09-139691

Noble, E. E., and Kanoski, S. E. (2016). Early life exposure to obesogenic diets and learning and memory dysfunction. Curr. Opin. Behav. Sci. 9, 7-14. doi: 10.1016/j.cobeha.2015.11.014

Noble, E. E., Hsu, T. M., Jones, R. B., Fodor, A. A., Goran, M. I., and Kanoski, S. E. (2017). Early-life sugar consumption affects the rat microbiome independent of obesity. J. Nutr. 147, 20-28. doi: 10.3945/jn.116.238816

Noble, E. E., Mavanji, V., Little, M. R., Billington, C. J., Kotz, C. M., and Wang, C. (2014). Exercise reduces diet-induced cognitive decline and increases hippocampal brain-derived neurotrophic factor in CA3 neurons. Neurobiol. Learn. Mem. 114, 40-50. doi: 10.1016/j.nlm.2014.04.006

Ohland, C. L., Kish, L., Bell, H., Thiesen, A., Hotte, N., Pankiv, E., et al. (2013). Effects of Lactobacillus helveticus on murine behavior are dependent on diet and genotype and correlate with alterations in the gut microbiome. Psychoneuroendocrinology 38, 1738-1747. doi: 10.1016/j.psyneuen.2013.02.008

Ojo, B., El-Rassi, G. D., Payton, M. E., Perkins-Veazie, P., Clarke, S., Smith, B. J., et al. (2016). Mango supplementation modulates gut microbial dysbiosis and short-chain fatty acid production independent of body weight reduction in C57BL/6 mice fed a high-fat diet. J. Nutr. 146, 1483-1491. doi: $10.3945 /$ jn. 115.226688

Ott, A., Stolk, R. P., van Harskamp, F., Pols, H. A., Hofman, A., and Breteler, M. M. (1999). Diabetes mellitus and the risk of dementia: the Rotterdam Study. Neurology 53, 1937-1942. doi: 10.1212/WNL.53.9.1937

Ouyang, S., Hsuchou, H., Kastin, A. J., Wang, Y., Yu, C., and Pan, W. (2014). Diet-induced obesity suppresses expression of many proteins at the blood-brain barrier. J. Cereb. Blood Flow Metab. 34, 43-51. doi: 10.1038/jcbfm.2013.166

Pallebage-Gamarallage, M., Lam, V., Takechi, R., Galloway, S., Clark, K., and Mamo, J. (2012). Restoration of dietary-fat induced blood-brain barrier dysfunction by anti-inflammatory lipid-modulating agents. Lipids Health Dis. 11:117. doi: 10.1186/1476-511X-11-117

Pavlik, V., Massman, P., Barber, R., and Doody, R. (2013). Differences in the association of peripheral insulin and cognitive function in non-diabetic Alzheimer's disease cases and normal controls. J. Alzheimers. Dis. 34, 449-456. doi: 10.3233/JAD-121999

Pendyala, S., Walker, J. M., and Holt, P. R. (2012). A high-fat diet is associated with endotoxemia that originates from the gut. Gastroenterology 142, 1100-1101.e2. doi: 10.1053/j.gastro.2012.01.034

Pistell, P. J., Morrison, C. D., Gupta, S., Knight, A. G., Keller, J. N., Ingram, D. K., et al. (2010). Cognitive impairment following high fat diet consumption is associated with brain inflammation. J. Neuroimmunol. 219, 25-32. doi: 10.1016/j.jneuroim.2009.11.010

Puig, K. L., Floden, A. M., Adhikari, R., Golovko, M. Y., and Combs, C. K. (2012). Amyloid precursor protein and proinflammatory changes are regulated in brain and adipose tissue in a murine model of high fat diet-induced obesity. PLoS ONE 7:e30378. doi: 10.1371/journal.pone.0030378

Rachal Pugh, C., Fleshner, M., Watkins, L. R., Maier, S. F., and Rudy, J. W. (2001). The immune system and memory consolidation: a role for the cytokine
IL-1beta. Neurosci. Biobehav. Rev. 25, 29-41. doi: 10.1016/S0149-7634(00)0 0048-8

Rainone, V., Schneider, L., Saulle, I., Ricci, C., Biasin, M., Al-Daghri, N. M., et al. (2016). Upregulation of inflammasome activity and increased gut permeability are associated with obesity in children and adolescents. Int. J. Obes. 40, 1026-1033. doi: 10.1038/ijo.2016.26

Ridaura, V. K., Faith, J. J., Rey, F. E., Cheng, J., Duncan, A. E., Kau, A. L., et al. (2013). Gut microbiota from twins discordant for obesity modulate metabolism in mice. Science 341:1241214. doi: 10.1126/science.1241214

Rönnemaa, E., Zethelius, B., Sundelöf, J., Sundström, J., DegermanGunnarsson, M., Berne, C., et al. (2008). Impaired insulin secretion increases the risk of Alzheimer disease. Neurology 71, 1065-1071. doi: 10.1212/01.wnl.0000310646.32212.3a

Sankowski, R., Mader, S., and Valdés-Ferrer, S. I. (2015). Systemic inflammation and the brain: novel roles of genetic, molecular, and environmental cues as drivers of neurodegeneration. Front. Cell. Neurosci. 9:28. doi: $10.3389 /$ fncel.2015.00028

Schneeberger, M., Everard, A., Gómez-Valadés, A. G., Matamoros, S., Ramírez, S., Delzenne, N. M., et al. (2015). Akkermansia muciniphila inversely correlates with the onset of inflammation, altered adipose tissue metabolism and metabolic disorders during obesity in mice. Sci. Rep. 5:16643. doi: $10.1038 /$ srep 16643

Segain, J. P., Raingeard de la Blétière, D., Bourreille, A., Leray, V., Gervois, N., Rosales, C., et al. (2000). Butyrate inhibits inflammatory responses through NFkappaB inhibition: implications for Crohn's disease. Gut 47, 397-403. doi: 10.1136/gut.47.3.397

Sellbom, K. S., and Gunstad, J. (2012). Cognitive function and decline in obesity. J. Alzheimers. Dis. 30(Suppl. 2), S89-S95. doi: 10.3233/JAD-2011-111073

Shin, N. R., Lee, J. C., Lee, H. Y., Kim, M. S., Whon, T. W., Lee, M. S., et al. (2014). An increase in the Akkermansia spp. population induced by metformin treatment improves glucose homeostasis in diet-induced obese mice. Gut 63, 727-735. doi: 10.1136/gutjnl-2012-303839

Simon, M. C., Strassburger, K., Nowotny, B., Kolb, H., Nowotny, P., Burkart, V., et al. (2015). Intake of Lactobacillus reuteri improves incretin and insulin secretion in glucose-tolerant humans: a proof of concept. Diabetes Care 38, 1827-1834. doi: 10.2337/dc14-2690

Stefanko, D. P., Barrett, R. M., Ly, A. R., Reolon, G. K., and Wood, M. A. (2009). Modulation of long-term memory for object recognition via HDAC inhibition. Proc. Natl. Acad. Sci. U.S.A. 106, 9447-9452. doi: 10.1073/pnas.0903964106

Stranahan, A. M., Hao, S., Dey, A., Yu, X., and Baban, B. (2016). Bloodbrain barrier breakdown promotes macrophage infiltration and cognitive impairment in leptin receptor-deficient mice. J. Cereb. Blood Flow Metab. 36, 2108-2121. doi: 10.1177/0271678X16642233

Stranahan, A. M., Norman, E. D., Lee, K., Cutler, R. G., Telljohann, R. S., Egan, J. M., et al. (2008). Diet-induced insulin resistance impairs hippocampal synaptic plasticity and cognition in middle-aged rats. Hippocampus 18, 1085-1088. doi: 10.1002/hipo. 20470

Suárez-Zamorano, N., Fabbiano, S., Chevalier, C., Stojanovic, O., Colin, D. J., Stevanovic, A., et al. (2015). Microbiota depletion promotes browning of white adipose tissue and reduces obesity. Nat. Med. 21, 1497-1501. doi: 10.1038/nm.3994

Sun, J., Wang, F., Li, H., Zhang, H., Jin, J., Chen, W., et al. (2015). Neuroprotective effect of sodium butyrate against cerebral ischemia/reperfusion injury in mice. Biomed. Res. Int. 2015:395895. doi: 10.1155/2015/395895

Sweat, V., Starr, V., Bruehl, H., Arentoft, A., Tirsi, A., Javier, E., et al. (2008). C-reactive protein is linked to lower cognitive performance in overweight and obese women. Inflammation 31, 198-207. doi: 10.1007/s10753-0089065-3

Tolhurst, G., Heffron, H., Lam, Y. S., Parker, H. E., Habib, A. M., Diakogiannaki, E., et al. (2012). Short-chain fatty acids stimulate glucagon-like peptide-1 secretion via the G-protein-coupled receptor FFAR2. Diabetes 61, 364-371. doi: $10.2337 / \mathrm{db} 11-1019$

Tsukumo, D. M., Carvalho-Filho, M. A., Carvalheira, J. B., Prada, P. O., Hirabara, S. M., Schenka, A. A., et al. (2007). Loss-of-function mutation in Toll-like receptor 4 prevents diet-induced obesity and insulin resistance. Diabetes 56, 1986-1998. doi: 10.2337/db06-1595

Tulstrup, M. V., Christensen, E. G., Carvalho, V., Linninge, C., Ahrné, S., Højberg, O., et al. (2015). Antibiotic treatment affects intestinal permeability and gut 
microbial composition in wistar rats dependent on antibiotic class. PLoS ONE 10:e0144854. doi: 10.1371/journal.pone.0144854

Turner, J. R. (2009). Intestinal mucosal barrier function in health and disease. Nat. Rev. Immunol. 9, 799-809. doi: 10.1038/nri2653

Vrieze, A., Van Nood, E., Holleman, F., Salojärvi, J., Kootte, R. S., Bartelsman, J. F., et al. (2012). Transfer of intestinal microbiota from lean donors increases insulin sensitivity in individuals with metabolic syndrome. Gastroenterology 143, 913-6.e7. doi: 10.1053/j.gastro.2012.06.031

Wang, Z., Xiao, G., Yao, Y., Guo, S., Lu, K., and Sheng, Z. (2006). The role of bifidobacteria in gut barrier function after thermal injury in rats. J. Trauma 61, 650-657. doi: 10.1097/01.ta.0000196574.70614.27

Winocur, G., Greenwood, C. E., Piroli, G. G., Grillo, C. A., Reznikov, L. R., Reagan, L. P., et al. (2005). Memory impairment in obese Zucker rats: an investigation of cognitive function in an animal model of insulin resistance and obesity. Behav. Neurosci. 119, 1389-1395. doi: 10.1037/0735-7044.119.5.1389

Wu, X., Chen, P. S., Dallas, S., Wilson, B., Block, M. L., Wang, C. C., et al. (2008). Histone deacetylase inhibitors up-regulate astrocyte GDNF and BDNF gene transcription and protect dopaminergic neurons. Int. J. Neuropsychopharmacol. 11, 1123-1134. doi: 10.1017/S1461145708009024

Yaffe, K., Blackwell, T., Kanaya, A. M., Davidowitz, N., Barrett-Connor, E., and Krueger, K. (2004). Diabetes, impaired fasting glucose, and development of cognitive impairment in older women. Neurology 63, 658-663. doi: 10.1212/01.WNL.0000134666.64593.BA
Yoo, D. Y., Kim, D. W., Kim, M. J., Choi, J. H., Jung, H. Y., Nam, S. M., et al. (2015). Sodium butyrate, a histone deacetylase inhibitor, ameliorates SIRT2-induced memory impairment, reduction of cell proliferation, and neuroblast differentiation in the dentate gyrus. Neurol. Res. 37, 69-76. doi: 10.1179/1743132814Y.0000000416

Zhang, C., Zhang, M., Pang, X., Zhao, Y., Wang, L., and Zhao, L. (2012). Structural resilience of the gut microbiota in adult mice under high-fat dietary perturbations. ISME J. 6, 1848-1857. doi: 10.1038/ismej.2012.27

Zhao, W. Q., and Alkon, D. L. (2001). Role of insulin and insulin receptor in learning and memory. Mol. Cell. Endocrinol. 177, 125-134. doi: 10.1016/S0303-7207(01)00455-5

Conflict of Interest Statement: The authors declare that the research was conducted in the absence of any commercial or financial relationships that could be construed as a potential conflict of interest.

Copyright (c) 2017 Noble, Hsu and Kanoski. This is an open-access article distributed under the terms of the Creative Commons Attribution License (CC BY). The use, distribution or reproduction in other forums is permitted, provided the original author(s) or licensor are credited and that the original publication in this journal is cited, in accordance with accepted academic practice. No use, distribution or reproduction is permitted which does not comply with these terms. 